Acta Crystallographica Section E

Structure Reports

Online

ISSN 1600-5368

\section{A second polymorph of carvedilol}

A second polymorph of the title compound [systematic name: 1-(9H-carbazol-4-yloxy)-3-[2-(2-methoxyphenoxy)ethylamino]propan-2-ol], $\mathrm{C}_{24} \mathrm{H}_{26} \mathrm{~N}_{2} \mathrm{O}_{4}$, is described. The other polymorph [Chen, Zeng, Yu \& Xu (1998). Jiegou Huaxue (Chin. J. Struct. Chem.), 17, 325-328] also crystallizes in the space group $P 2_{1} / c$, but differs in two torsion angles of the chain connecting the aromatic residues. On the other hand, the hydrogen-bond patterns of the two polymorphs are rather similar.

\section{Comment}

Carvedilol, $\mathrm{C}_{24} \mathrm{H}_{26} \mathrm{~N}_{2} \mathrm{O}_{4}$, is a non-selective $\beta$-adrenergic blocking agent with $\alpha 1$-blocking activity indicated for the treatment of congestive heart failure (CHF). It is the first $\beta$ blocker labelled in the United States especially for the treatment of heart failure of ischemic or cardiomyopathic origin with significant antioxidant activity (Ruffolo et al., 1990; Feuerstein et al., 1995; Zeng et al., 2003).

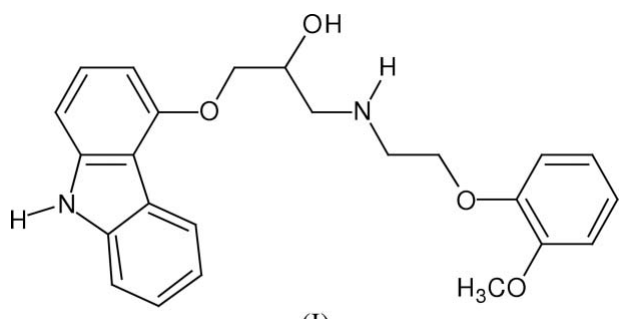

(I)

The crystal structure of carvedilol was described in space group $P 2_{1} / c$ (Chen et al., 1998). We now report a second polymorph of carvedilol, (I) (Fig. 1), in the same space group, which differs in two key torsion angles. The bond lengths and angles for (I) can be regarded as normal (Cambridge Structural Database, Version 5.27, November 2005, updated August 2006; Mogul Version 1.1; Allen, 2002). The structure of (I) shows several significant differences from the already known (Chen et al., 1998) polymorph, (II). Although both structures are monoclinic and crystallize in the same space group, the cell parameters are completely different [for (II), $a=9.094$ (1) $\AA$, $b=12.754$ (1) $\AA, c=18.330$ (2) $\AA$ and $\left.\beta=97.36(1)^{\circ}\right]$. The molecular conformations of (I) and (II) are totally different, but a closer look reveals that only two torsion angles are in fact responsible for this difference (Table 1). Whereas the conformation about the $\mathrm{C} 2-\mathrm{C} 3$ bond is antiperiplanar in (I), it is synclinal in (II), and the conformation about O8-C81 is anticlinal in (I) but synclinal in (II). A least-squares fit (Fig. 2) of the matching torsion angles (i.e. fitting the chain from $\mathrm{C} 2$ to
Received 2 January 2007 Accepted 4 January 2007 


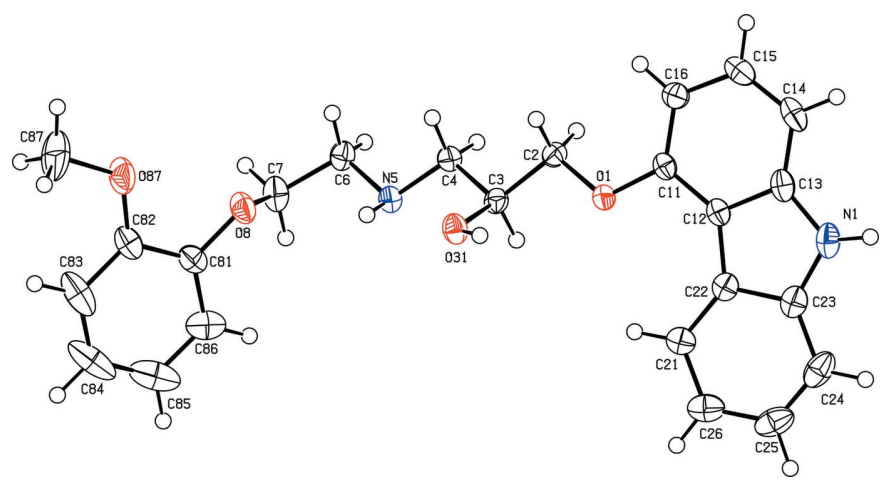

Figure 1

The molecular structure of (I), showing $50 \%$ probability displacement ellipsoids (arbitrary spheres for the $\mathrm{H}$ atoms).

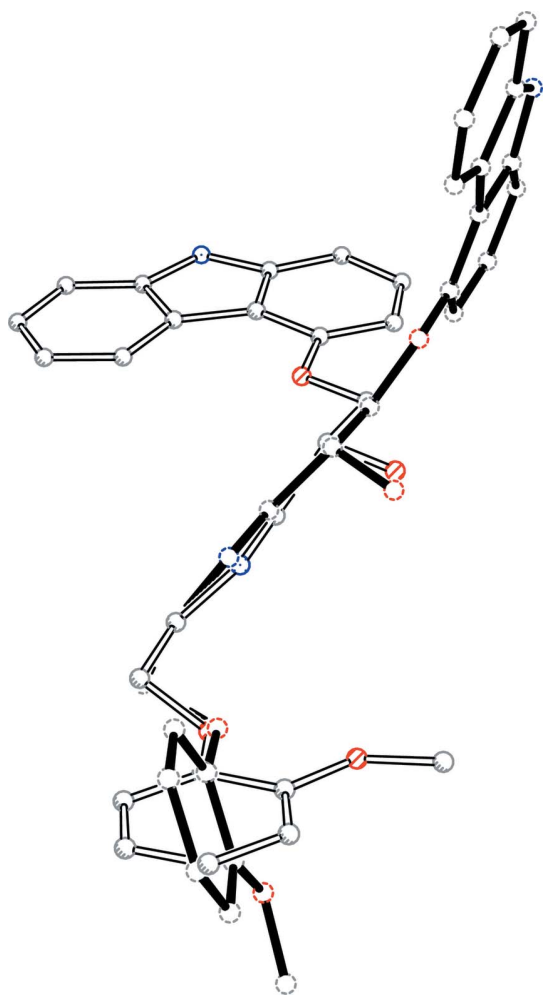

Figure 2

Least-squares overlap of the main backbones of (I) (full bonds) and (II) (open bonds).

O8; r.m.s. deviation $=0.134 \AA$ ) shows the similarities and differences of (I) and (II).

Nevertheless, the two classical hydrogen bonds in (I) are also present in (II) (Tables 2 and 3). The carbazole $\mathrm{N}$ atom forms an intermolecular hydrogen bond to the methoxy $\mathrm{O}$ atom $\mathrm{O} 87$ and the hydroxyl group forms an intermolecular hydrogen bond to the amino $\mathrm{N}$ atom. However, whereas it is a 2 screw axis that generates the second molecule for the $\mathrm{N}_{\mathrm{c}}-$ $\mathrm{H} \cdots \mathrm{O}(\mathrm{c}=$ carbazole) hydrogen bond in (I) and (II), the symmetry operation for generating the second molecule for the $\mathrm{O}-\mathrm{H} \cdots \mathrm{N}$ hydrogen bond is a $c$-glide plane in (I), but an inversion centre in (II). The amino $\mathrm{H}$ atom has close contacts to the hydroxyl $\mathrm{O}$ atom and the ether $\mathrm{O}$ atom (Tables 2 and 3 ), but the $\mathrm{H} \cdots \mathrm{O}$ distances are rather long and the $\mathrm{N}-\mathrm{H} \cdots \mathrm{O}$ angles are rather small.

\section{Experimental}

Carvedilol was obtained as a gift sample from Cadila Pharmaceuticals, Gujarat, India. X-ray quality crystals of (I) were obtained from toluene by slow evaporation (m.p. 385-387 K).
Crystal data

$\mathrm{C}_{24} \mathrm{H}_{26} \mathrm{~N}_{2} \mathrm{O}_{4}$

$M_{r}=406.47$

Monoclinic, $P 2_{1} / c$

$a=15.5414$ (14) А

$b=15.2050(12) \AA$

$c=9.1174(8) \AA$

$\beta=100.730(7)^{\circ}$

$V=2116.8(3) \AA^{3}$

Data collection

Stoe IPDS-II two-circle diffractometer

$\omega$ scans

Absorption correction: none

12521 measured reflections

\section{Refinement}

Refinement on $F^{2}$

$R\left[F^{2}>2 \sigma\left(F^{2}\right)\right]=0.040$

$w R\left(F^{2}\right)=0.106$

$S=1.03$

3956 reflections

285 parameters

$\mathrm{H}$ atoms treated by a mixture of independent and constrained refinement

$$
\begin{aligned}
& Z=4 \\
& D_{x}=1.275 \mathrm{Mg} \mathrm{m}^{-3} \\
& \text { Mo } K \alpha \text { radiation } \\
& \mu=0.09 \mathrm{~mm}^{-1} \\
& T=173(2) \mathrm{K} \\
& \text { Block, colourless } \\
& 0.36 \times 0.33 \times 0.32 \mathrm{~mm}
\end{aligned}
$$

3956 independent reflections 3060 reflections with $I>2 \sigma(I)$ $R_{\text {int }}=0.034$

$\theta_{\max }=25.7^{\circ}$

\section{Table 1}

Selected torsion angles $\left(^{\circ}\right.$ ) for (I) and (II).

\begin{tabular}{lrr}
\hline & \multicolumn{1}{c}{$(\mathrm{I})$} & \multicolumn{1}{c}{ (II) } \\
\hline $\mathrm{C} 12-\mathrm{C} 11-\mathrm{O} 1-\mathrm{C} 2$ & $164.14(11)$ & -175.2 \\
$\mathrm{C} 11-\mathrm{O} 1-\mathrm{C} 2-\mathrm{C} 3$ & $-173.50(11)$ & 177.2 \\
O1-C2-C3-C4 & $170.44(11)$ & 59.2 \\
C2-C3-C4-N5 & $178.21(12)$ & 175.0 \\
C4-N5-C6-C7 & $169.95(12)$ & 167.3 \\
C6-C7-O8-C81 & $161.69(13)$ & 159.8 \\
C7-O8-C81-C82 & $129.41(15)$ & -150.7 \\
\hline
\end{tabular}

Table 2

Hydrogen-bond geometry $\left(\AA{ }^{\circ}\right)$.

\begin{tabular}{lllll}
\hline$D-\mathrm{H} \cdots A$ & $D-\mathrm{H}$ & $\mathrm{H} \cdots A$ & $D \cdots A$ & $D-\mathrm{H} \cdots A$ \\
\hline $\mathrm{O} 31-\mathrm{H} 31 \cdots \mathrm{N} 5^{\mathrm{i}}$ & $0.92(2)$ & $2.09(2)$ & $2.9633(16)$ & $158(2)$ \\
$\mathrm{N} 1-\mathrm{H} 1 \cdots \mathrm{O} 87^{\mathrm{ii}}$ & $0.94(2)$ & $2.11(2)$ & $3.0336(19)$ & $167.4(18)$ \\
$\mathrm{N} 5-\mathrm{H} 5 \cdots \mathrm{O} 8$ & $0.910(19)$ & $2.456(18)$ & $2.8619(17)$ & $107.3(13)$ \\
$\mathrm{N} 5-\mathrm{H} 5 \cdots \mathrm{O} 31$ & $0.910(19)$ & $2.443(17)$ & $2.8198(17)$ & $105.0(13)$ \\
\hline
\end{tabular}

Symmetry codes: (i) $x,-y+\frac{1}{2}, z+\frac{1}{2}$; (ii) $-x+1, y+\frac{1}{2},-z+\frac{3}{2}$. 
Table 3

Hydrogen bond parameters for (II).

\begin{tabular}{lllll}
\hline$D-\mathrm{H} \cdots A$ & $D-\mathrm{H}$ & $\mathrm{H} \cdots A$ & $D \cdots A$ & $D-\mathrm{H} \cdots A$ \\
\hline $\mathrm{O}-\mathrm{H} \cdots \mathrm{N}^{\mathrm{iii}}$ & 1.14 & 1.73 & 2.837 & 173 \\
$\mathrm{~N}_{\text {carbazole }}-\mathrm{H} \cdots \mathrm{O}^{\mathrm{iv}}$ & 0.90 & 2.35 & 3.193 & 156 \\
$\mathrm{~N}_{\text {amino }}-\mathrm{H} \cdots \mathrm{O}_{\text {ether }}$ & 0.90 & 2.48 & 2.828 & 103 \\
$\mathrm{~N}_{\text {amino }}-\mathrm{H} \cdots \mathrm{O}_{\text {hydroxyl }}$ & 0.90 & 2.70 & 2.872 & 92
\end{tabular}

The geometrical values for the $\mathrm{O}-\mathrm{H} \cdots \mathrm{N}$ bond were taken from the original publication. The other values were determined by us with $\mathrm{H}$ atoms placed in calculated positions. Symmetry codes: (iii) $1-x,-y,-z$; (iv) $1-x, \frac{1}{2}+y, \frac{1}{2}-z$.

The $\mathrm{H}$ atoms were found in a difference map. Those bonded to $\mathrm{C}$ were relocated in idealized locations $(\mathrm{C}-\mathrm{H}=0.95-1.00 \AA)$ and refined as riding with $U_{\text {iso }}(\mathrm{H})=1.2 U_{\text {eq }}(\mathrm{C})$ or $1.5 U_{\text {eq }}($ methyl C). The positions and $U_{\text {iso }}$ values for the $\mathrm{H}$ atoms bonded to $\mathrm{N}$ and $\mathrm{O}$ were freely refined.

Data collection: $X$-AREA (Stoe \& Cie, 2001); cell refinement: $X$-AREA; data reduction: $X$-AREA; program(s) used to solve structure: SHELXS97 (Sheldrick, 1997); program(s) used to refine structure: SHELXL97 (Sheldrick, 1997); molecular graphics:
PLATON (Spek, 2003) and XP in SHELXTL-Plus (Sheldrick, 1991); software used to prepare material for publication: PLATON and SHELXL97.

SB thanks the University of Mysore and TVS thanks Mangalore University for research facilities.

\section{References}

Allen, F. H. (2002). Acta Cryst. B58, 380-388.

Chen, W.-M., Zeng, L.-M., Yu, K.-B. \& Xu, J.-H. (1998). Jiegou Huaxue (Chin. J. Struct. Chem.), 17, 325-328.

Feuerstein, G. Z., Poste, G. \& Ruffolo, R. R. (1995). Drugs Today, 31, 307326.

Ruffolo, R. R. Jr, Gellai, M., Heible, J. P., Willette, R. N. \& Nichols, A. J. (1990). Eur. J. Clin. Pharmacol. 38 (Suppl 2), 82-88.

Sheldrick, G. M. (1991). SHELXTL-Plus. Release 4.1. Siemens Analytical X-ray Instruments Inc., Madison, Wisconsin, USA.

Sheldrick, G. M. (1997). SHELXS97 and SHELXL97. University of Göttingen, Germany.

Spek, A. L. (2003). J. Appl. Cryst. 36, 7-13.

Stoe \& Cie (2001). $X$-AREA. Stoe \& Cie, Darmstadt, Germany.

Zeng, H., Liu, X. \& Zhao, H. (2003). J. Huazhong Univ. Sci. Technol. Med. Sci. 23, 127-130. 